\title{
Management of a case of high-risk gastrointestinal stromal tumor in rectum by transanal minimal invasive surgery
}

Pramod Nepal, Shinichiro Mori", Yoshiaki Kita, Kan Tanabe, Kenji Baba, Yasuto Uchikado, Hiroshi Kurahara, Takaaki Arigami, Masahiko Sakoda, Kosei Maemura and Shoji Natsugoe

\begin{abstract}
Background: Rectal gastrointestinal stromal tumor (GIST) is a very rare tumor of gastrointestinal tract. Surgical management of rectal GIST requires special attention for preserving of anal and urinary functions. Transanal minimal invasive surgery (TAMIS) is a well-developed minimally invasive technique for local excision of benign and early malignant rectal tumors; however, the application of TAMIS for rectal GIST is rarely and inadequately reported. We report the novel application of TAMIS for rectal GIST with considerations for anal and urinary functions.

Case presentation: A 67 years old female, who presented with history of per rectal bleeding, was diagnosed with submucosal GIST of $4.5 \mathrm{~cm}$ in diameter at right posterior wall of $7 \mathrm{~cm}$ from anal verge. Histology of biopsy showed abundant spindle-shaped cells arranged in bundles that were positive for CD34 and negative for C-Kit, desmin, smooth muscle actin (SMA), and S-100. The tumor was excised by TAMIS successfully. Final histopathology showed pT2 tumor with C-Kit positive and mitosis count 10 per 50 HPF. Postoperative period was uneventful, and she was discharged on adjuvant imatinib mesylate for 3 years.

Conclusion: TAMIS can be used safely in the management of rectal GIST after appropriate evaluation of tumor size, extent, location, and experience of operating surgeon.
\end{abstract}

Keywords: Rectal GIST, TAMIS, Imatinib mesylate

\section{Background}

Gastrointestinal stromal tumor (GIST) is a rare tumor of the gastrointestinal (GI) tract that constitutes less than $1 \%$ of all GI tumors. Nevertheless, they are the commonest of all the mesenchymal tumors of the GI tract [1]. The usual sites of occurrence are the stomach (60-70\%), intestines $(20-30 \%)$, colon and rectum (5\%), and esophagus $(<5 \%)[2]$. GISTs in the rectum demonstrate male predominance and rarely occur in individuals younger than 40 years [3].

Various surgical techniques have been described for the treatment of rectal GIST, including traditional transanal resection, trans-sacral approach, transanal endoscopic microsurgery (TEM), transanal minimal invasive

\footnotetext{
* Correspondence: morishin@m3.kufm.kagoshima-u.ac.jp Department of Digestive Surgery, Breast and Thyroid Surgery, Graduate School of Medicine, Kagoshima University, Sakuragaoka 8-35-1, Kagoshima 890-8520, Japan
}

surgery (TAMIS), and laparoscopic surgery [4-11]. Although TAMIS has been undergoing a surge in popularity among surgeons, its application for management of rectal GISTs is rarely reported, and only few cases of rectal GISTs are included in large series of TAMIS [5, 6]. Here, we discuss a high-risk case of rectal GIST that was managed by TAMIS with due consideration for preserving anal and urinary functions and by postoperative adjuvant therapy with imatinib mesylate (IM).

\section{Case presentation}

A 67-year-old female patient presented with a complaint of per rectal bleeding. Computed tomography (CT) and magnetic resonance imaging (MRI) showed a tumor $4.5 \mathrm{~cm}$ in diameter in right posterior wall of the middle rectum with no adjacent infiltration or lymph node metastasis (Fig. 1a, b). Colonoscopy revealed a submucosal mass in the right posterior wall of the middle rectum 


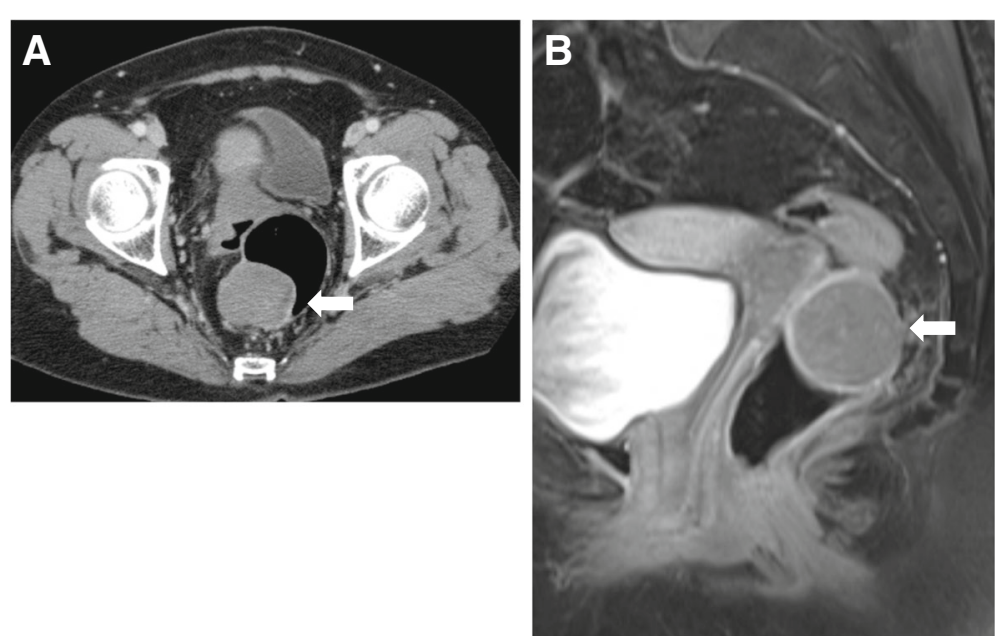

Fig. $1 C T$ and MRI examinations. a CT scan of pelvis showing tumor $4.5 \mathrm{~cm}$ in diameter (white arrowhead). b MRI showing tumor at middle rectum (white arrowhead)

$7 \mathrm{~cm}$ from anal verge (Fig. 2). Histologically, a biopsy showed spindle-shaped cells arranged in bundles, positive for CD34 and negative for C-Kit, Desmin, smooth muscle actin, and S-100 (Fig. 3). These findings suggested a rectal GIST, and TAMIS was scheduled.

The patient was kept in the modified lithotomy position, and the anus dilated with a self-retaining anal retractor (Lone Star Retractor; Cooper Surgical, Trumbull, CT, USA). A transanal access device (GelPOINT path; Applied Medical, Rancho Santa Margarita, CA, USA) was introduced. Wet gauze was inserted above the lesion, and pneumorectum was maintained at $15 \mathrm{mmHg}$ with carbon dioxide by an AirSeal platform (AirSeal system; CONMED, Utica, NY, USA). Conventional laparoscopic instruments were used. The tumor was located at

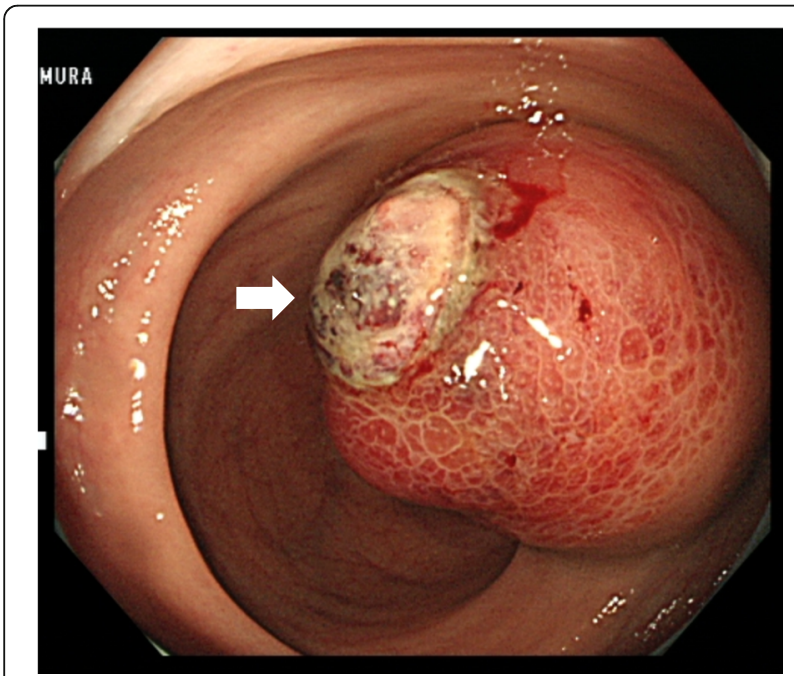

Fig. 2 Colonoscopic image showing tumor with ulcer in right lateral wall of middle rectum (arrowhead) the right posterior wall in the middle rectum; the incision site $1 \mathrm{~cm}$ away from the tumor margin was tattooed circumferentially. Mucosal dissection was performed along the tattoo (Fig. 4a), and subsequent full-thickness excision was carried out (Fig. 4b, c). The tumor was peeled off and extracted using an Endo Catch specimen pouch (Medtronic, Minneapolis, MN, USA) to avoid dissemination (Fig. 4d). Intraluminal lavage with saline was performed, and hemostasis was secured (Fig. 5a). The defect was closed with 3-0 V-Loc (Medtronic) under $8 \mathrm{mmHg}$ pressure by the AirSeal system (Fig. 5b, c). The specimen measuring $4.5 \mathrm{~cm} \times 4.5 \mathrm{~cm} \times 3.5 \mathrm{~cm}$ (Fig. $5 \mathrm{~d}$ ) was sent for histopathology, which confirmed a pT2 rectal GIST positive for KIT (CD117) and CD34. The resection margin was negative, and the mitosis count was 10 per 50 high-power fields. The postoperative period was uneventful with normal anal and urinary functions. The patient was discharged on IM (Gleevec), $400 \mathrm{mg}$ once daily for 3 years under regular follow-up.

\section{Discussion}

Surgery with complete resection is the only curative option for rectal GISTs [1]. It is very important to consider the balance of radical resection with the preservation of the anal and urinary functions in the treatment of middle to lower rectal GISTs. Various surgical techniques have been described for rectal GISTs, including conventional transanal resection, trans-sacral approach, transanal endoscopic microsurgery (TEM), transanal minimal invasive surgery (TAMIS), and laparoscopic surgery [4-11]. Clinicians need to adopt these approaches according to appropriate evaluation of tumor size, extent, and location, as well as the operating surgeon's experience of the techniques.

TEM, which had better access to proximal rectum and good surgical field of vision, provides superior quality of 

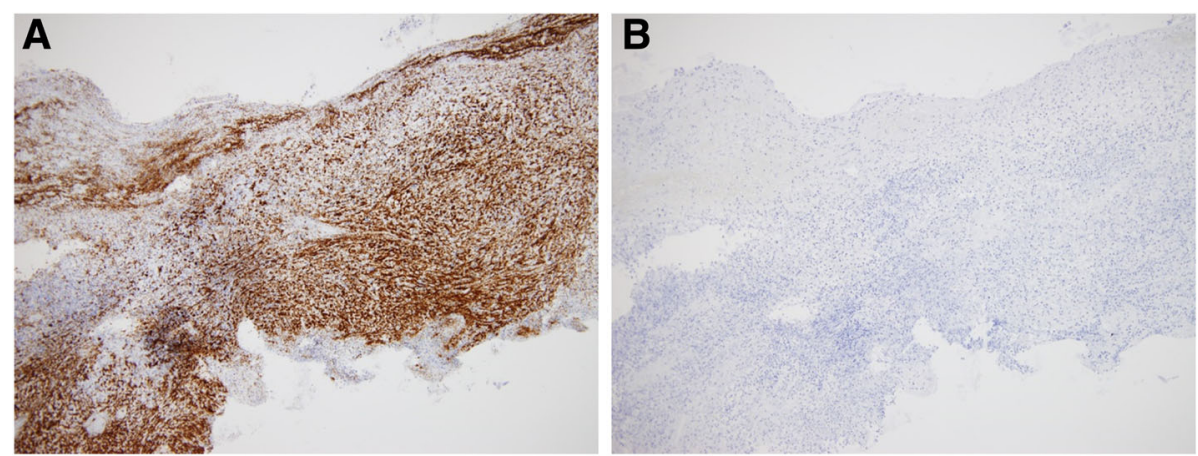

Fig. 3 Histopathology of biopsy. a The biopsy was positive for CD34. b The biopsy was negative for C-kit

resection, decreased local recurrence compared to conventional transanal excision for selected patients with rectal lesions $[12,13]$. Compared with the abdominoperineal resection (APR) and some other function-preserving procedures, TEM also is much more minimally invasive with less morbidity and better life quality for selective patients $[12,13]$. However, TEM has been slow to become universally adopted by colorectal surgeons, in part because of a steep learning curve, but also because of the significant cost of the highly specialized instrumentation [14-16]. TAMIS was first reported by Atallah as a hybrid between TEM and single-port laparoscopy in 2010, who concluded that TAMIS is a feasible alternative to TEM, providing its benefits at a fraction of the cost [16]. We adopted TAMIS using GelPOINT path as a surgical management of our case. The technique yielded good visualization of operation field and allowed precisely full thickness excision of the tumor with preserving mesorectum, resulting in preserving urinary function. However, when patients have a tumor larger than $5 \mathrm{~cm}$ in diameter or very close to the anal verge, the adoption of laparoscopic APR or other function-preserving procedures is unavoidable. Table 1 shows the summary of surgical options for resection of rectal GIST. In our case, TAMIS was able to be applied because the tumor was $4.5 \mathrm{~cm}$ in diameter with no metastasis and was located in the mid-rectum. Postoperatively,
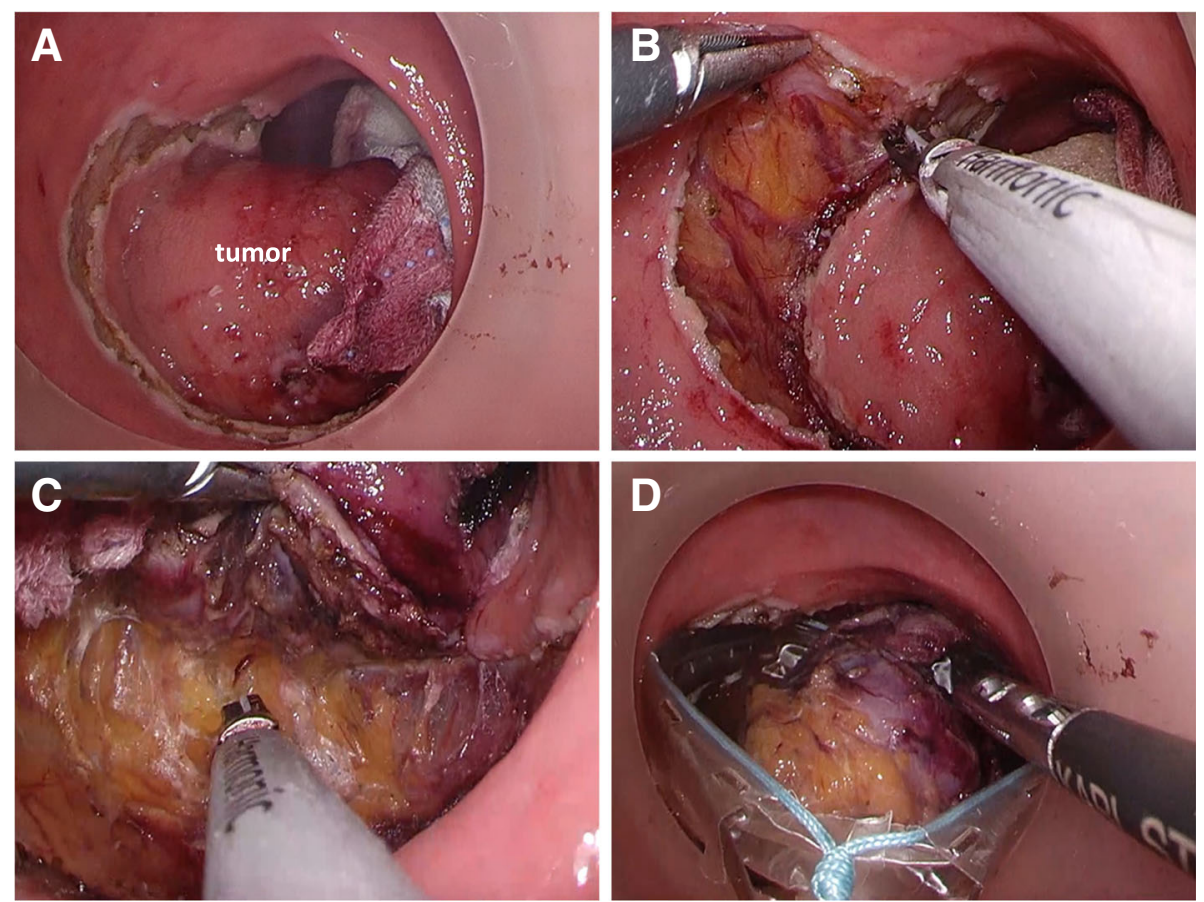

Fig. 4 Surgical procedure. a Mucosal dissection performed along the tattoo circumferentially $1 \mathrm{~cm}$ from the tumor margin. b Full-thickness dissection of tumor performed circumferentially. $\mathbf{c}$ Dissection performed between rectum and mesorectum on the posterior wall. $\mathbf{d}$ Extraction of the tumor using the Endo Catch specimen pouch 

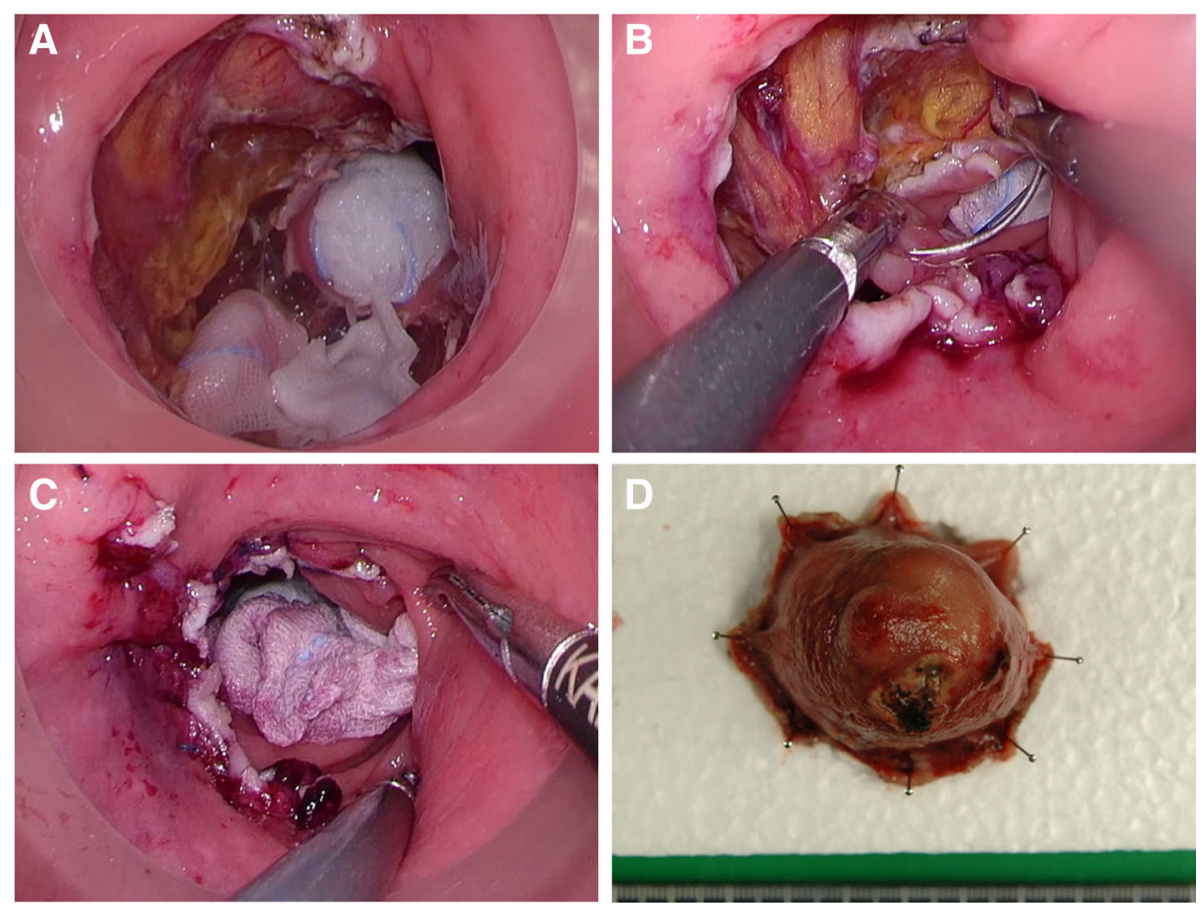

Fig. 5 Defect closure and retrieved specimen. a Intraluminal lavage with saline and securing hemostasis. b Closing the defect with 3-0 V-Loc under $8 \mathrm{mmHg}$ pressure under the AirSeal system. c Final view of surgical site after repair of rectal defect (LDQ). $\mathbf{d}$ The specimen measuring $4.5 \mathrm{~cm} \times 4.5 \mathrm{~cm} \times 3.5 \mathrm{~cm}$

the patient had satisfactory anal and urinary function, with no recurrence or metastasis at the 12-month follow-up.

With surgery alone, the 15 years recurrence-free survival (RFS) and overall survival (OS) time was found to be $59.9 \%$ and 12.4 years respectively [17]. Use of IM as an adjuvant therapy can increase resectability or decrease surgical morbidity in unresectable or locally advanced cases and can improve recurrence-free survival [4]. The tumor size, mitosis count, non-gastric location, male sex, and rupture of pseudocapsule are the independent adverse prognostic factors for GIST [17]. In our case, the tumor diameter was $4.3 \mathrm{~cm}$ and initial biopsy was negative for $\mathrm{C}$-Kit, so we proceeded with curative surgery rather than neoadjuvant IM. Neoadjuvant IM is recommended if R0 resection is not possible, surgery can be achieved by less mutilating surgery/functional preserving surgery, or can be made safer [18]. In our case, the mitosis count was 10 per $50 \mathrm{HPF}$, so it was considered

Table 1 Summary of surgical procedures for the resection of rectal GIST

\begin{tabular}{|c|c|c|c|c|c|}
\hline S.N & Procedure & Benefits & Demerits & Cost & Morbidity rate. \\
\hline 1. & Local trans-anal resection $[6,12]$ & $\begin{array}{l}\text { - Used usually for lower rectal } \\
\text { lesions } \\
\text { - Easy and minimally invasive }\end{array}$ & $\begin{array}{l}\text { Local recurrences is high due to } \\
\text { poor quality of excision and } \\
\text { fragmentation of tumor }\end{array}$ & Cheaper & Up to $22 \%$ \\
\hline 2. & Trans-sacral resection $[11,20]$ & $\begin{array}{l}\text { Beneficial for GISTS that are large } \\
\text { and grow away from rectal lumen }\end{array}$ & $\begin{array}{l}\text { - More invasive than TAMIS } \\
\text { - Increased risk of poor perineal } \\
\text { wound healing and fecal fistula }\end{array}$ & Cheaper & Up to $21 \%$ \\
\hline 3. & $\operatorname{TEM}[12,16]$ & $\begin{array}{l}\text { Superior quality of resection, } \\
\text { decreased local recurrence, and } \\
\text { improved survival }\end{array}$ & $\begin{array}{l}\text { - Anorectal dysfunction may occur } \\
\text { due to rigid anoscope } \\
\text { - Steep learning curve and need } \\
\text { of highly qualified surgeon }\end{array}$ & Expensive than TAMIS & Up to $29 \%$ \\
\hline 4. & TAMIS $[6,16]$ & $\begin{array}{l}\text { - Superior operative results } \\
\text { - Convenient access device and } \\
\text { less effects on anorectal } \\
\text { functions }\end{array}$ & $\begin{array}{l}\text { Difficult to access upper rectum } \\
\text { and not suitable for large tumors }\end{array}$ & Reasonable cost & Up to $7.4 \%$ \\
\hline
\end{tabular}


high-risk malignant GIST [19] and patient was discharged on adjuvant IM for 3 years.

This case provided a new strategy consisting of TAMIS using GelPOINT path with conventional laparoscopic instruments for patients with small size of tumor less than $5 \mathrm{~cm}$ in diameter. However, prospective studies are needed in the future to investigate safety and effects of this new strategy.

\section{Conclusion}

Rectal GIST is one of the most important differential diagnoses of rectal tumor that requires special consideration with regard to preservation of anal and urinary functions when the tumor is small. In our case, TAMIS using GelPOINT path contributed to curative resection of the tumor and satisfactory functions. The appropriate surgical technique should be selected depending upon location, size, and resectability of tumor, and the surgical expertise of the attending physician.

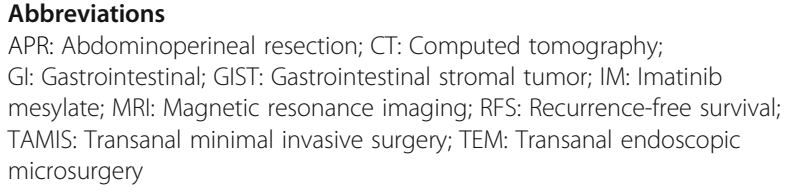

\section{Acknowledgements}

We appreciate the contributions of all the surgeons, coworkers, and friends involved in this study and thank the editors and reviewers for their help with this manuscript. We also thank Hugh McGonigle, from Edanz Group (www.edanzediting.com/ac), for editing a draft of the manuscript.

\section{Authors' contribution}

PN and SM conceived of the study, designed it, and acquired the data. YK, KT, $K B, Y U, H K, T A, M S$, and KM participated in design of the study and coordination and analysis of data. PN drafted the manuscript. SN participated in manuscript preparation and critical revision. All authors read and approved the manuscript.

\section{Availability of data and materials}

The data and materials can be made available whenever inquired.

\section{Ethics approval and consent to participate}

Consent to participate was obtained.

\section{Consent for publication}

Consent for publication of images and necessary data was taken.

\section{Competing interests}

We declare no competing interests.

\section{Publisher's Note}

Springer Nature remains neutral with regard to jurisdictional claims in published maps and institutional affiliations.

Received: 18 February 2018 Accepted: 1 August 2018 Published online: 11 August 2018

\section{References}

1. Blackstein ME, Dubé $P$, Fletcher JA, Keller OR, Knowling M, Létourneau R, Morris D, Riddell R, Rorke S, Swallow CJ. Gastrointestinal stromal tumours: etiology, pathology and clinical management. Can J Gastroenterol Hepatol. 2004;18(Suppl B):3B-8B.
2. Miettinen M, Lasota J. Gastrointestinal stromal tumors-definition, clinical, histological, immunohistochemical, and molecular genetic features and differential diagnosis. Virchows Arch. 2001;438(1):1-2.

3. Miettinen M, Furlong M, Sarlomo-Rikala M, Burke A, Sobin LH, Lasota J. Gastrointestinal stromal tumors, intramural leiomyomas, and leiomyosarcomas in the rectum and anus: a clinicopathologic, immunohistochemical, and molecular genetic study of 144 cases. Am J Surg Pathol. 2001;25(9):1121-33.

4. Wilkinson MJ, Fitzgerald JE, Strauss DC, Hayes AJ, Thomas JM, Messiou C, Fisher C, Benson C, Tekkis PP, Judson I. Surgical treatment of gastrointestinal stromal tumour of the rectum in the era of imatinib. Br J Surg. 2015;102(8): 965-71.

5. Quaresima S, Balla A, Franceschilli L, La Torre M, lafrate C, Shalaby M, Di Lorenzo N, Sileri P. Transanal minimally invasive surgery for rectal lesions. J Soc Laparoendosc Surg. 2016;20(3):e2016.00032. https://doi.org/10.4293/ JSLS.2016.00032

6. Martin-Perez B, Andrade-Ribeiro GD, Hunter L, Atallah S. A systematic review of transanal minimally invasive surgery (TAMIS) from 2010 to 2013. Tech Coloproctol. 2014;18(9):775-88.

7. Keller DS, Tahilramani RN, Flores-Gonzalez JR, Mahmood A, Haas EM. Transanal minimally invasive surgery: review of indications and outcomes from 75 consecutive patients. J Am Coll Surg. 2016;222(5):814-22.

8. Liu Q, Zhong G, Zhou W, Lin G. Initial application of transanal endoscopic microsurgery for high-risk lower rectal gastrointestinal stromal tumor after imatinib mesylate neoadjuvant chemotherapy: a case report. Medicine (Baltimore). 2017:96(29):e7538.

9. Kyo K, Azuma M, Okamoto K, Nishiyama M, Shimamura T, Maema A, Kanamaru H, Shirakawa M, Nakamura T, Shinmura K, Koda K, Yokoyama H. Neoadjuvant imatinib treatment and laparoscopic anus-preserving surgery for a large gastrointestinal stromal tumor of the rectum. World I Surg Oncol. 2016;14:68. https://doi.org/10.1186/s12957-016-0837-1.

10. Nozawa H, Kanazawa T, Tanaka T, Takahashi M, Ishihara S, Sunami E, Kitayama J, Ikemura M, Komuro I, Watanabe T. Laparoscopic resection of a gastrointestinal stromal tumor of the lower rectum in a patient with coronary artery disease following long-term neoadjuvant imatinib treatment and anticoagulation therapy. World J Surg Oncol. 2014;12:211. https://doi.org/10. 1186/1477-7819-12-211.

11. Gervaz P, Huber O, Bucher P, Sappino P, Morel P. Trans-sacral (Kraske) approach for gastrointestinal stromal tumour of the lower rectum: old procedure for a new disease. Color Dis. 2008;10(9):951-2. https://doi.org/10. 1111/j.1463-1318.2008.01489.x. Epub 2008 Feb 22

12. Christoforidis D, Cho HM, Dixon MR, Mellgren AF, Madoff RD, Finne CO. Transanal endoscopic microsurgery versus conventional transanal excision for patients with early rectal cancer. Ann Surg. 2009;249(5):776-82.

13. Neary P, Makin GB, White TJ, White E, Hartley J, MacDonald A, Lee PW, Monson JR. Transanal endoscopic microsurgen: a viable operative alternative in selected patients with rectal lesions. Ann Surg Oncol. 2003;10:1106-11.

14. Papagrigoriadis $\mathrm{S}$. Transanal endoscopic micro-surgery (TEMS) for the management of large or sessile rectal adenomas: a review of the technique and indications. Int Semin Surg Oncol. 2006:3:13.

15. Maslekar S, Pillinger SH, Sharma A, Taylor A, Monson JR. Cost analysis of transanal endoscopic microsurgery for rectal tumours. Color Dis. 2007;9(3): 229-34

16. Atallah $\mathrm{S}$, Albert $\mathrm{M}$, Larach $\mathrm{S}$. Transanal minimally invasive surgery: a giant leap forward. Surg Endosc. 2010;24(9):2200-5.

17. Joensuu $H$, Vehtari $A$, Riihimäki J, Nishida T, Steigen SE, Brabec P, Plank L, Nilsson B, Cirilli C, Braconi C, Bordoni A. Risk of recurrence of gastrointestinal stromal tumour after surgery: an analysis of pooled population-based cohorts. Lancet Oncol. 2012:13(3):265-74.

18. ESMO/European Sarcoma Network Working Group. Gastrointestinal stromal tumours: ESMO Clinical Practice Guidelines for diagnosis, treatment and follow-up. Annals of oncology: official journal of the European Society for Medical Oncology/ESMO. Ann Oncol. 2014;25:iii21.

19. Fletcher CD, Berman JJ, Corless C, Gorstein F, Lasota J, Longley BJ, Miettinen M, O'leary TJ, Remotti H, Rubin BP, Shmookler B. Diagnosis of gastrointestinal stromal tumors: a consensus approach. Hum Pathol. 2002; 33(5):459-65.

20. Terkivatan T, den Hoed PT, Lange JF, Koot VC, van Goch JJ, Veen HF. The place of the posterior surgical approach for lesions of the rectum. Dig Surg. 2005;22(1-2):86-90. 